\title{
Article
}

\section{Preparing Biology Graduate Teaching Assistants for Their Roles as Instructors: An Assessment of Institutional Approaches}

\author{
Elisabeth E. Schussler, ${ }^{*}$ Quentin Read, ${ }^{*}$ Gili Marbach-Ad, ${ }^{+}$Kristen Miller, ${ }^{\ddagger}$ \\ and Miriam Ferzli ${ }^{\S}$
}

*Department of Ecology and Evolutionary Biology, University of Tennessee, Knoxville, Knoxville, TN 37996; ${ }^{+}$CMNS Teaching and Learning Center, University of Maryland, College Park, MD 20742; Sciences, University of Georgia, Athens, GA 30602; §Department of Biology, North Carolina State University, Raleigh, NC 27695

Submitted November 2, 2014; Revised April 6, 2015; Accepted April 14, 2015

Monitoring Editor: Diane Ebert-May

\begin{abstract}
The inconsistency of professional development (PD) in teaching for graduate teaching assistants (GTAs) is a widespread problem in higher education. Although GTAs serve an important role in retention of undergraduate science majors and in promotion of scientific literacy in nonmajors, they often lack preparation and ongoing support for teaching. Given the recent national focus on instructional quality in introductory courses, our goal was to use an online survey to identify current practices of teaching PD for biology GTAs and compare these results with the last national survey on this topic. In responses from 71 participant institutions, 96\% reported some mandatory teaching preparation for biology GTAs; however, 52\% of these programs required 10 or fewer hours per year. Respondents wanted to change their programs to include more pedagogical information and teaching observations with feedback to their GTAs. Programmatic self-ratings of satisfaction with GTA PD were positively correlated with the number of topics discussed during PD. Although more schools are requiring GTA PD for teaching compared with the last national survey, the lack of program breadth at many schools warrants a national conversation with regard to recent calls for improving undergraduate instruction.
\end{abstract}

\section{INTRODUCTION}

Biology graduate teaching assistants (GTAs) provide instruction for many of the small class sections (typically, labs or discussion) associated with introductory and gateway majors' and nonmajors' biology courses at research

CBE Life Sci Educ September 2, 2015 14:ar31

DOI:10.1187/cbe-14-11-0196

Address correspondence to: Elisabeth E. Schussler (eschussl@utk .edu).

(C) 2015 E. E. Schussler et al. CBE-Life Sciences Education (c) 2015 The American Society for Cell Biology. This article is distributed by The American Society for Cell Biology under license from the author(s). It is available to the public under an Attribution-Noncommercial-Share Alike 3.0 Unported Creative Commons License (http:/ / creativecommons.org/licenses/by-nc-sa/3.0).

"ASCB®" and "The American Society for Cell Biology ${ }^{\circledR}$ " are registered trademarks of The American Society for Cell Biology. universities across the United States (Sundberg et al., 2005). These are the same courses that have been the focus of recent national efforts to increase science, technology, engineering, and mathematics retention and increase scientific literacy for nonmajors (Association of American Universities, 2011; President's Council of Advisors on Science and Technology [PCAST], 2012). Scholars have also called attention to the importance of the quality of instruction provided by instructors of these courses (American Association for the Advancement of Science [AAAS], 2011; Freeman et al., 2014). As a result, many pedagogical improvement efforts have been directed toward science faculty members. Despite these efforts in training biology faculty members, fewer opportunities for developing teaching are available to GTAs. Given that GTAs have more one-on-one contact with students in large introductory courses than faculty members (Rushin et al., 1997), more attention should be given to this group of instructors. 
Professional development (PD) of biology GTAs has been a historically neglected aspect of academia (Boyer Commission on Educating Undergraduates in the Research University, 1998; Golde and Dore, 2001; Gardner and Jones, 2011). Although many graduate students are paid through teaching assistant positions that require them to teach undergraduate courses, GTAs often receive conflicting information about the value of teaching, including being told not to devote much time to their teaching duties (Nyquist et al., 1999). Many graduate students are encouraged to develop their skills as researchers but are rarely encouraged to develop their proficiency at teaching (Brownell and Tanner, 2012). Given this typical prioritization of research over teaching, GTAs have reported that little is done to promote their teaching abilities (Austin, 2002; Austin et al., 2009; Luft, et al., 2004). This is in contrast to the reality that many GTAs are interested in teaching (Tanner and Allen, 2006) and anticipate that teaching will be part of their future professional careers (Sauermann and Roach, 2012). Departments and institutions could make a positive impact on both the teaching abilities of future faculty members and the development of appropriate teacher/scholar professional identities if they invested more time and resources in GTA PD (Brownell and Tanner, 2012; Kendall et al., 2013).

Many studies have suggested that the PD of GTAs does not focus on the important pedagogical and discipline-specific knowledge necessary for teaching. It is generally focused on logistics and classroom management rather than discussion of pedagogical practices that foster student learning (Luft et al., 2004; Hardre, 2012). In fact, GTAs often comment that they are given little feedback about their teaching by course supervisors (Austin, 2002; DeChenne et al., 2012). In one study, $25 \%$ of GTAs reported they had no supervision of their teaching at all (Prieto, 2001). Because GTA PD is rarely discipline-specific (Park, 2004), GTA PD programs in undergraduate biology teaching may fail to provide GTAs with support to foster inquiry skills and an understanding of the process of science in their undergraduate students, especially as they relate to learning in the laboratory context (Park, 2004; Honeycutt et al., 2010; Ferzli et al., 2012).

The last national survey of biology GTA PD practices was conducted by Rushin et al. (1997), who surveyed 153 graduate schools of biology across the country. Almost all of the schools $(97 \%)$ reported using GTAs as instructors in labs or lectures. The authors classified masters- and doctoral-granting institutional responses about formal opportunities for GTA PD into five categories: 1) no formal training provided, 2) mentoring by faculty members with occasional seminars, 3) pre-academic year workshop with occasional other meetings, 4) required seminar during teaching semester, and 5) formal course on college teaching. The results of this survey found that $49 \%$ of the universities provided no teaching preparation for biology GTAs. For $22 \%$ of the schools, the primary PD was the pre-academic year workshop, while $14 \%$ required a seminar during their teaching semester, and $8 \%$ required a formal college teaching course. Mentoring by a faculty member comprised only $7 \%$ of the responses. Rushin and coauthors reached the conclusion that the minimal and brief amount of formal teaching preparation was unlikely to effectively prepare GTAs for either their teaching responsibilities at the institution or their potential roles as future faculty members.
Since 1997, many authors have reported on new deliveries of traditional semester-based teaching PD courses and new ways to approach formal and informal GTA PD. For example, the literature describes several new models for half-semester or semester-long courses for science GTAs (Baumgartner, 2007; Schussler et al., 2008; Marbach-Ad et al., 2010, 2012a; Lockwood et al., 2014). Some institutions have also implemented extensions to traditional single-day workshops, such as multiday, presemester orientations (Young and Bippus, 2008); programs that include a presemester orientation, a teaching seminar, PD in lab prep meetings, and teaching observations (Gormally et al., 2011); and optional teaching certificate programs (Addy and Blanchard, 2010; Honeycutt et al., 2010, Marbach-Ad et al., 2015b). Hardre and Burris (2012) created a hybrid online and on-site GTA PD orientation with choices of breakout sessions. Some researchers have detailed specific training approaches, such as instructional design (Hardre, 2005), laboratory teaching apprenticeships (Bond-Robinson and Rodriques, 2006), and lesson study (Dotger, 2011). Others have advocated using lab preparation meetings as explicit venues for GTA instructional preparation (Nurrenbern et al., 1999; Trautwein, 1999; Wyse et al., 2014). Beyond formal PD sessions, however, there has also been a suggestion to add more informal PD and peer support into GTA PD programs (Gardner and Jones, 2011), such as observations with feedback and reflection (Miller et al., 2014) or the creation of teaching communities for GTAs (Hardre and Chen, 2005; Ash et al., 2009).

In the context of current calls for science education teaching reform and the lack of a systematic survey of GTA PD opportunities since 1997, we were led to ask: what is the current state of GTA PD at institutions across the nation, and is there any indication that PD for biology GTAs has changed since 1997? Such questions led to the development of the Biology Teaching Assistant Project (BioTAP) in 2013 with funding from the National Science Foundation's Research Coordination Network program. The BioTAP network aims to link people and resources with the goal of improving the teaching practices of biology graduate students. To inform this initiative, in late Fall 2013, the BioTAP steering committee conducted a national survey of current institutional GTA PD practices. The specific research questions for the study were:

1. What are the types of GTA PD programs at the respondents' institutions?

2. What PD topics are covered in the GTA programs?

3. How are GTAs and/or PD programs assessed and evaluated?

4. What are the factors correlated with respondent satisfaction with their GTA PD?

5. Is there evidence that GTA PD has changed since 1997?

The resulting data were used to provide a focus for BioTAP's efforts to improve the PD for teaching offered to biology graduate students.

\section{METHODS}

\section{Data Collection}

During the Summer of 2013, the BioTAP steering committee held an intensive 2-d meeting to plan for the project. Before 
the meeting, every committee member was asked to research at least two institutional examples of teaching PD opportunities for biology GTAs. During the meeting, we shared these examples and synthesized the diversity of practices represented by these institutions. Using a summary of this discussion and the categories proposed by Rushin et al. (1997) as a starting point, two of the coauthors (E.E.S. and Q.R.) built the online survey in Fall 2013. Importantly, the BioTAP survey contained detailed questions that probed current PD practices more thoroughly. For example, Rushin et al. (1997) asked one open-ended question and then categorized the responses based on the structure of the PD opportunities. The structure of PD was explored in our survey as well, but we also included additional topics for institutional response such as: the length of the formal PD sessions, the content covered, informal PD available, assessment methods, and how satisfied faculty/staff respondents were with a program. Survey questions were a mix of predetermined categories to select from (e.g., multiple-choice and Likert-type response questions) and open-ended responses. This allowed not only for the compilation of practices in defined categories but also enabled respondents to report on new practices that may not have been included as survey choices.

The survey was reviewed for face validity by the BioTAP steering committee and was pilot tested by a faculty member and a postdoc not affiliated with the project; the faculty member was a lab supervisor and PD course leader, the postdoc was affiliated with a GTA PD program. We revised the survey based on this collective feedback to clarify wording and add or remove questions based on what reviewers felt was most or least applicable to their own programs and experiences with GTA PD. A link to the revised survey with explanatory text was sent directly to 336 individuals identified as being likely to be involved in training of biology GTAs at all of the research-active universities (master's and doctoral-granting) in the United States and Canada. The individuals identified for direct contact were either coordinators of introductory courses or biology programs, discipline-based biology educators, or, in the absence of the first two options, department chairs; we targeted these individuals because we felt they would have the most knowledge about GTA PD practices and therefore would be most likely to provide accurate information. The text and link were also sent to mailing lists of the Society for the Advancement of Biology Education Research and the Association for Biology Laboratory Education, because these were judged to be the organizations most likely to attract faculty and staff members who provide PD to biology GTAs. By combining direct emails to individuals with emails to these mailing lists, the authors intended to reach a majority of professionals involved in biology GTA PD rather than attempting to collect a random sample of respondents.

The full survey consisted of 21 questions; this report focuses on the responses to only 17 of the questions, nine closed-response and eight open-ended questions (see the Supplemental Materials for the full survey). Two of the questions regarding how contextual factors at different institutions impacted PD programs were confusing to respondents (based on open-ended comments) and thus were discarded. We also did not compile responses from two of the last questions, as those were specifically designed to collect information for the network and not to inform the research questions. The survey was not anonymous, enabling the removal of duplicate responses from individuals involved in the same departmental PD programs (responses from individuals at the same institution but directing different departmental programs were retained). The survey and research were approved by the first author's institutional review board (UTK IRB-14-09318 B-XP), and all respondents in this report gave explicit consent via an email response.

The survey contained four categories of questions (detailed below): demographic information, types of GTA PD offered, topics covered by GTA PD, and assessment of GTA PD. The questions on types, topics, and assessment were used to answer research questions 1 through 3, respectively. Research question 4 used data from several survey categories, while research question 5 was answered by resorting the responses provided about types of GTA PD as described in the Data Analysis section.

\section{Respondent Demographic Information}

Questions in this category asked for respondents' names, job titles, departments, institutional positions (faculty or staff members), course(s) for which they train GTAs, level of GTA PD involvement (institution, college, department, and/ or course), type of course their GTAs teach (e.g., introductory and/or upper-level), and the pedagogical approach of the course (open inquiry, guided inquiry, or cookbook). No definitions of these pedagogical approaches were included in the survey, allowing respondents to self-select their perceived pedagogical approaches.

\section{Type of GTA PD at the Respondent Institution}

Respondents were asked to select the types of formal PD opportunities (defined, structured offerings such as orientations or courses) available to biology GTAs at their institutions, report whether these opportunities were optional or mandatory, and estimate how long each lasted (from a given list of time ranges). They were also asked about specific informal PD programs (e.g., mentoring, peer support, observations), and whether they were optional or mandatory. Finally, respondents answered an open-ended question asking for an estimate of the minimum number of hours a GTA at their institution would spend in PD per year. Respondents were given the opportunity to clarify any of their checked responses via comment boxes.

\section{PD Topics Provided in the GTA Programs}

Respondents were presented with six PD topics (teaching policies, classroom management, course content, teaching techniques, learning theory, and lesson planning) that were initially identified as PD categories by the BioTAP steering committee. They were asked to indicate which topics were currently covered in their PD sessions and which topics they wished were provided. The survey did not ask respondents to indicate the length of time, quality, or type of PD session in which a topic was presented, only whether a topic was addressed during their PD sessions. A text box, however, did allow respondents to clarify their coverage or add any items that they did discuss in their program that were not represented among those six categories. 


\section{Assessment of GTA PD}

Respondents were asked which assessment tools (e.g., surveys of GTAs, student surveys, and/or teaching observations) were used at their institutions to evaluate the effectiveness of their GTA PD programs. This was followed by an open-ended question asking what assessment tools they would like to have available to evaluate their GTA PD programs. Respondents also provided a Likert-type response to two questions: the perceived level of institutional support for their GTA PD programs and the respondents' overall satisfaction with the biology GTA PD at their institutions ( 1 being low and 5 being high for both questions). The last question of the survey asked them to list one thing they wished they could change about the GTA PD at their institutions and the aspects of GTA PD with which a network such as BioTAP could help them.

\section{Data Analysis}

As mentioned above, all survey questions were either predefined categories from which respondents selected a response (closed response) or comment boxes in which respondents could provide open-ended responses. These closed- and open-response questions in all categories of the survey were analyzed as described below to directly answer research questions 1 through 3 and to inform the analysis for research questions 4 and 5 .

For the closed-response questions, the percent responses per answer choice were tallied. For questions related to institutional PD, the responses of respondents from the same institution (11 institutions) were compiled into one answer to avoid duplicate responses in the results. In four cases, respondents from the same institutions provided conflicting information about whether institutional orientations were mandatory or not; if one said it was mandatory, we used that as our response for the institution. For other responses about departmental or course GTA PD, all responses were treated independently.

Answers to the open-response questions were read and analyzed independently by two of the coauthors (E.E.S. and Q.R.). The coauthors first read all responses and developed categories they felt represented the majority of the responses. They then conferred with each other about their categories and discussed their ideas to reach a consensus about the final categories (Maykut and Morehouse, 1994). Each then reread the responses and placed them into the categories they had developed; this allowed them to tally the number of responses for each category. It should be noted that respondents could provide responses in more than one category. For example, someone may have indicated that they would want to change their program by having more faculty involvement and providing more pedagogy to GTAs. Those responses were tallied once in each of those categories.

To assess research question four regarding the relative influence of different GTA PD factors on self-reported respondent satisfaction with the overall PD program at each institution, we used a proportional-odds multiple regression model (Hutcheson, 2013). This technique allowed us to model the multiple Likert scale levels of self-reported satisfaction (1-5, where 1 is very low and 5 is very high) and determine the effect each predictor variable has on the odds that a response would be in a relatively higher satisfaction category. In this model, a regression coefficient is estimated for each predictor variable, and a different intercept is estimated for the transition between each category (very low to low, low to medium, and so on). A positive coefficient indicates that an increase in the predictor variable increases the relative odds of the response being in a higher category.

The predictor variables in the multiple regression model were 1) the minimum number of mandatory PD hours required annually for each GTA at each institution, which was considered to be a surrogate for intensity of PD; 2) the total number of topics covered in PD of the six described above, which was a proxy for the breadth of PD; and 3) the number of reported feedback opportunities (whether mandatory or optional) provided to GTAs by each institution, including peer mentoring, faculty mentoring, online mentoring, observations, and discussion of student evaluations, which was considered a proxy for the level of feedback provided to GTAs.

We identified the total mandatory hours of PD per GTA per year either directly from the open-ended response provided to this question on the survey or from a compilation of respondent answers. Compilations were necessary, because $31 \%(N=85)$ of the responses to this question were either not usable or were inconsistent with other survey responses. Specifically, 20\% of the respondents said that this number was "unknown" or "variable" or they left the question blank. In $11 \%$ of the responses, the number provided was slightly different from the information provided in the survey. For example, some respondents said that $0 \mathrm{~h}$ of PD were provided but had indicated in another section of the survey that there was a mandatory presemester orientation at their institution. In these cases, the researchers looked at the respondents' responses regarding mandatory PD sessions and their lengths to estimate the total hours of PD their GTAs experienced. For the $11 \%$ of responses in which there were discrepant numbers, the average difference was $4.3 \mathrm{~h}$.

We fitted a model with all three predictors and also created reduced models with all possible subsets of predictors and a null model with only intercepts fitted, and used Akaike's information criterion (AIC) to determine which model best explained the data. Because only 49 respondents included information on all three predictors, this reduced set of respondents was used to fit all the models. In addition to this analysis, we also conducted a polychoric correlation (Drasgow, 1986) to assess the relationship between the Likert ratings of respondents' satisfaction with their GTA PD programs and the level of institutional support they felt was provided to their GTA PD programs (both on the same 1-5 Likert scale). Statistical analyses were performed using R 3.1.2 statistical computing language (R Core Team, 2014).

To analyze the final research question about evidence for changes to GTA PD since 1997, we directly compared our results with the most recent nationwide GTAPD survey (Rushin et al., 1997). To do so, we reanalyzed our survey data on biology GTA PD types to categorize our institutional results into the same groupings the 1997 survey used. Their categories were mutually exclusive, meaning that institutions could only belong to a single category. Thus, we started by binning each institution into either "no formal PD," "mentoring as only PD," or "pre-academic year workshop." We also further subdivided our "pre-academic year workshop" category into two categories: only presemester sessions versus presemester 
sessions plus other required in-semester meetings. It was difficult to sort into the "seminar during teaching semester" and "formal college course" categories, because it was unknown how Rushin and colleagues would categorize PD during lab preparation meetings (which was a fairly common form of PD on our survey). Thus, we merged these two categories into one category that we called "formal PD during semester only"; this comprised $22 \%$ of the sample in the original survey. In all cases, sorting was based on mandatory PD at each institution, not what was optional.

\section{RESULTS}

\section{Respondent Demographics}

There were 108 initial responses to the survey; 23 were removed because of incomplete responses or lack of consent. Overall, 85 respondents (63 faculty members and 22 staff members) from 71 different institutions completed the survey. There were multiple respondents (two to three) from 11 different institutions, but these were faculty or staff members working with different courses or departments. Most respondents were involved with $\mathrm{PD}$ at the level of a course $(58 \%)$ and/or the department/division (53\%). Four respondents were involved in GTA PD at the college or institutional level, and nine were involved at multiple departmental levels. Slightly more than half (51\%) were preparing GTAs to teach introductory biology course sections, while 37\% were focused on both introductory- and upper-level course preparation. The labs or courses the respondents were preparing GTAs to teach varied, yet $88 \%$ of the respondents were preparing GTAs to teach guided-inquiry or open-inquiry courses. Only four respondents indicated they were preparing GTAs to teach only cookbook labs.

Below we present our findings according to our five research questions.

\section{What Are the Types of GTA PD Programs at the Respondents' Institutions?}

Presemester PD. Responses about institutional presemester PD offerings were summarized by institution $(N=71$; i.e., not individual respondents). Twenty percent of institutions reported that presemester institutional PD was not offered, $27 \%$ indicated it was offered but optional, and $45 \%$ reported it was mandatory (Figure 1). Information about departmental presemester GTA orientations was tallied by respondents; $34 \%$ reported it was not offered, $7 \%$ reported it was offered but optional, and 51\% reported it was mandatory (Figure 1). For presemester course-specific orientations, 13\% reported not offering them, $8 \%$ said they were optional, and $73 \%$ reported they were mandatory (Figure 1). For all three presemester options, the most common length of the session was 2 to $5 \mathrm{~h}$ long.

In-Semester PD. Sixty-eight percent of the responding institutions had institutional pedagogical seminars during the semester that were optional for GTAs to attend, but only $4 \%$ said they were mandatory. Departmental pedagogical seminars were not widely available ( $44 \%$ of respondents), while $13 \%$ indicated they were mandatory. Almost half of the respondents (46\%) reported that teaching certificate programs

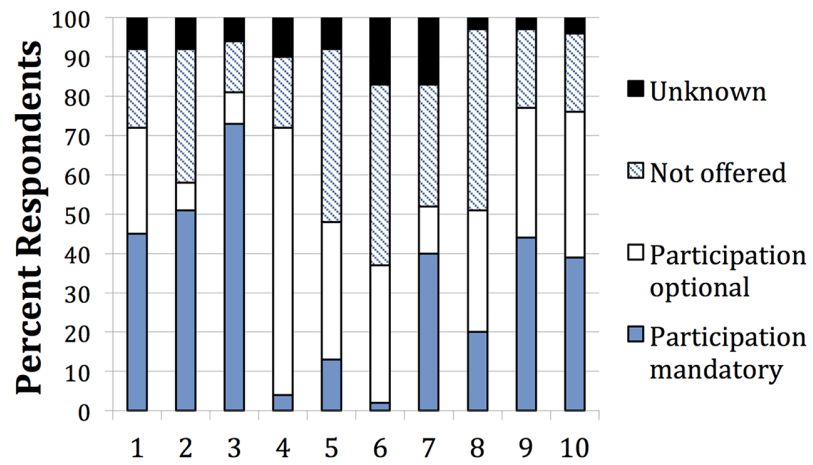

Figure 1. Types of PD programs described by respondents at different institutions, along with whether they were mandatory, optional, not offered, or of unknown status. Key: 1 = presemester institutional orientation ("tallied by institution, not respondent), 2 = presemester departmental orientation, 3 = presemester course orientation, $4=$ in-semester institutional PD, $5=$ in-semester departmental pedagogical seminar, $6=$ teaching certificate program, $7=\mathrm{PD}$ during lab preparatory meetings, $8=$ peer mentoring, $9=$ teaching observation, and $10=$ review of teaching evaluations.

were not available to their GTAs. Finally, $40 \%$ of the respondents indicated that PD during lab preparation meetings was mandatory for their GTAs, 31\% said it was not offered, and $12 \%$ said it was optional.

In total, the average number of different PD types (e.g., orientations and seminars) that were mandatory for GTAs was 2.3. Six respondents (7\%) reported there was no mandatory PD at their institutions, although three of those had colleagues at the same institution who indicated there was mandatory PD. Four different types of PD were mandatory for $21 \%$ of institutions. Overall, $88 \%$ of respondents indicated some sort of mandatory presemester PD, while $49 \%$ required some form of PD during the semester. The estimates for the number of hours that GTAs spent in PD for teaching ranged from 0 to $100 \mathrm{~h}$, with the average being $16.6 \mathrm{~h}$. Five respondents said that their schools require 50 or more hours of PD for their GTAs. A little more than half $(52 \%)$ of respondents said their required training was $10 \mathrm{~h}$ or less.

Informal PD. The most common mandatory types of informal PD were teaching observations with feedback (44\%) and discussion of student evaluation results (39\%). Twenty percent of programs offered neither option. Peer mentoring $(20 \%)$ and faculty mentoring (13\%) were less likely to be mandatory and far more likely to be not offered at all (46 and $51 \%$, respectively).

\section{What PD Topics Are Covered in the GTA Programs?}

The most common PD topics covered by programs were: teaching policies (91\% of respondents), classroom management $(84 \%)$, how to teach specific content $(82 \%)$, and teaching techniques (77\%; Figure 2). When asked what PD topics they wished were offered in their programs, $47 \%$ wanted more information about student learning theories and 38\% wanted more about planning lessons (the two topics least likely to be currently covered). Thirty-two respondents added comments or clarifications after this question, and of those, five 


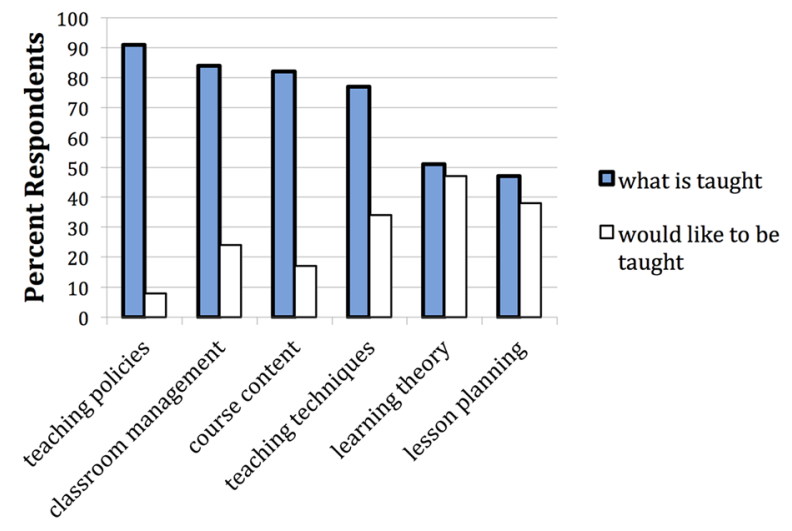

Figure 2. Percent of respondents saying they discuss each of the six PD topics with their GTAs and percent of respondents who wished that they taught more of each of the six topics to their GTAs. Topics: teaching policies, classroom management, course content, teaching techniques, learning theory, and lesson planning.

added that they talk about grading or student assessment in their GTA PD sessions.

\section{How Are GTAs and/or PD Programs Assessed and Evaluated?}

Assessment of PD. The most common way that respondents assessed their PD programs was by student evaluations of GTA instruction (81\%), followed by observations of GTA teaching (65\%) and surveys of GTA satisfaction (35\%; Figure $3)$. Other assessment methods respondents gave as open responses included: peer evaluations, GTA interviews, assessment of student learning, GTA self-reflection, and student assessment of labs (one response for each of these forms of assessment). Of the 44 respondents who added comments about what assessments they would like to have available,

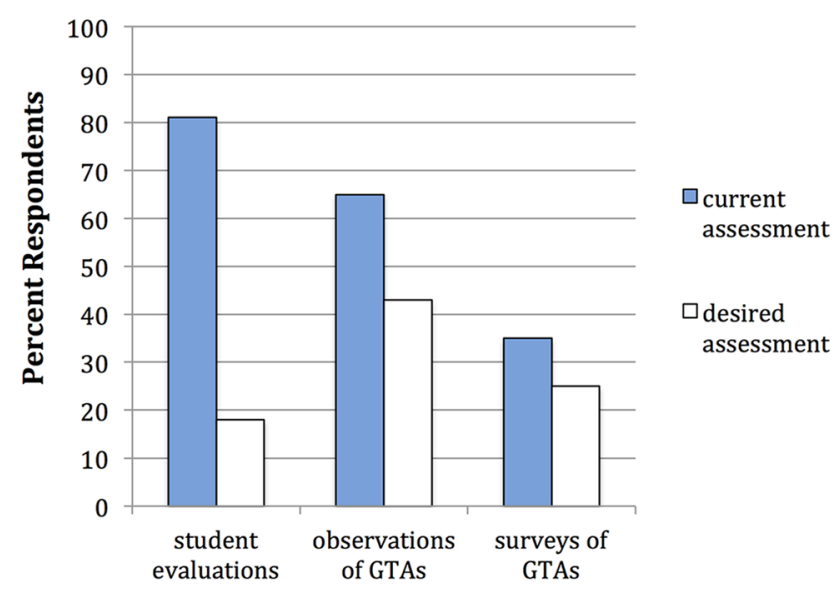

Figure 3. The percentage of respondents who currently use each of three types of GTA PD assessments (student evaluations of GTAs, observations of GTA teaching, and surveys of GTA satisfaction with the PD program) to evaluate their programs, and percentage of open-ended responses $(N=44)$ indicating their desire to use the same three assessments for their GTA PD program.

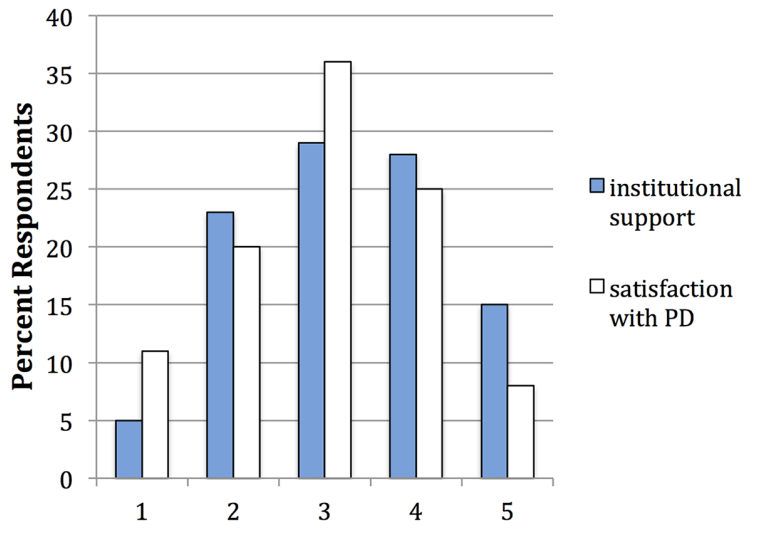

Figure 4. Distribution of Likert scale responses (1 being very low and 5 being very high) for respondents' self-rating of institutional support for GTA PD $(N=82)$ and respondents' satisfaction with their GTA PD programs $(N=80)$. Institutional support and respondent satisfaction with their programs were significantly positively related to each other $(p<0.001)$.

eight indicated they wanted better student evaluation surveys; 11 indicated they would like to have surveys of GTA satisfaction, especially validated surveys; and 19 said they wanted to do GTA teaching observations, particularly using a rubric or defined protocol.

Satisfaction and Institutional Support. In rating the biology GTA PD at their institutions, 33\% of respondents rated their satisfaction level as high or very high, 36\% reported that it was average, and $31 \%$ indicated that it was low or very low. Their perception of institutional support for GTA PD was slightly higher, with $43 \%$ of respondents saying it was high or very high, $29 \%$ reporting it was average, and $28 \%$ reporting it was low or very low (Figure 4 ).

What to Change. When asked what one thing they wished they could change about their GTA PD program ( $N=78$ total comments), three responses were most prevalent (Table 1; this table also includes supporting quotes). The most common response was for their institutions to have additional training on pedagogy as part of their GTA PD (39\% mentioned this). Some respondents also mentioned wanting more observations and feedback to GTAs about their teaching $(N=7)$. Finally, some respondents $(N=8)$ wanted to see increased faculty support and acknowledgment for the value of GTA teaching and training.

\section{What Are the Factors Correlated with Respondent Satisfaction with Their GTA PD?}

In our multiple regression model, the full model (including all three predictors: PD intensity, PD breadth, and amount of feedback) was found to be the best fit $(\triangle \mathrm{AIC}=7.8$ relative to the next-best model). However, although all three predictors were included in the best model, only PD breadth as measured by number of topics covered by PD program had a coefficient significantly greater than zero $(\beta=0.67 \pm 0.22 ; t$ $=2.982, p=0.001)$; the coefficients for the minimum number of hours spent $(\beta=0.002 \pm 0.015 ; t=0.162, p=0.44)$ and types of feedback provided $(\beta=0.15 \pm 0.25 ; t=0.615, p=0.27)$ were not significantly different from zero (Figure 5 ). This result 
Table 1. Most prevalent responses $(N=78)$ and supporting quotes to the open-ended question about what survey respondents would want to change about their GTA PD programs

\begin{tabular}{|c|c|}
\hline Most prevalent responses & Supporting quotes \\
\hline $\begin{array}{l}\text { Additional training on } \\
\text { pedagogy as part of GTA PD } \\
\text { (39\% of respondents) }\end{array}$ & $\begin{array}{l}\text { "We would require that all GTAs } \\
\text { enroll in a semester-long semi- } \\
\text { nar focused on teaching (educa- } \\
\text { tional research and practice)." } \\
\text { "Require all graduate students } \\
\text { to take a course in teaching } \\
\text { pedagogy and practice in their } \\
\text { discipline that incorporates } \\
\text { feedback on concurrent class- } \\
\text { room teaching to the graduate } \\
\text { students." }\end{array}$ \\
\hline $\begin{array}{l}\text { Observations of GTA teaching } \\
\text { with feedback ( } 9 \% \text { of } \\
\text { respondents) }\end{array}$ & $\begin{array}{l}\text { "The single change I would make } \\
\text { would be to offer more train- } \\
\text { ing to GTAs to improve their } \\
\text { teaching including teaching, } \\
\text { observations and feedback." }\end{array}$ \\
\hline $\begin{array}{l}\text { Faculty support and } \\
\text { acknowledgment of the } \\
\text { value of GTA PD (10\% of } \\
\text { respondents) }\end{array}$ & $\begin{array}{l}\text { "If the faculty supported teach- } \\
\text { ing to a larger extent, many } \\
\text { would not see professional } \\
\text { development of their graduate } \\
\text { students as the waste of } \\
\text { valuable research time that } \\
\text { many do." } \\
\text { "Authentic support ... for the } \\
\text { value of the TA experience, } \\
\text { and commitment to using } \\
\text { their own TAs in a manner } \\
\text { that contributes to profession- } \\
\text { al development." }\end{array}$ \\
\hline
\end{tabular}

indicates that the quality of PD provided in terms of topics covered, but not necessarily the quantity in terms of number of hours, has a positive impact on the success of the PD program as measured by the program coordinator's level of satisfaction. We also found a correlation coefficient of 0.798 \pm 0.043 between the respondents' ratings of their satisfaction with their GTA PD programs and their ratings of the level of institutional support for GTA PD (chi-square $=37.9, d f=15$, $p<0.001)$.

\section{Is There Evidence That GTA PD Has Changed Since 1997?}

While Rushin et al. (1997) reported that $49 \%$ of schools offered no GTA PD training at all, only $4 \%$ of our survey respondents (three institutions out of 71) indicated that their institutions had no mandatory GTA PD (Table 2). Similarly, while Rushin and coworkers found that $22 \%$ of schools offered presemester orientations, we found that $92 \%$ of institutions in our survey offered some type of mandatory presemester orientation (at the institutional, departmental, or course level). Of these, 31 schools (48\%) had no additional PD requirements, while 34 schools (52\%) had additional in-semester requirements, such as a departmental seminar or PD during lab preparation meetings. Three schools (4\%) offered mandatory PD during the semester as their only form of PD; by comparison, Rushin et al. (1997) found $22 \%$ in this
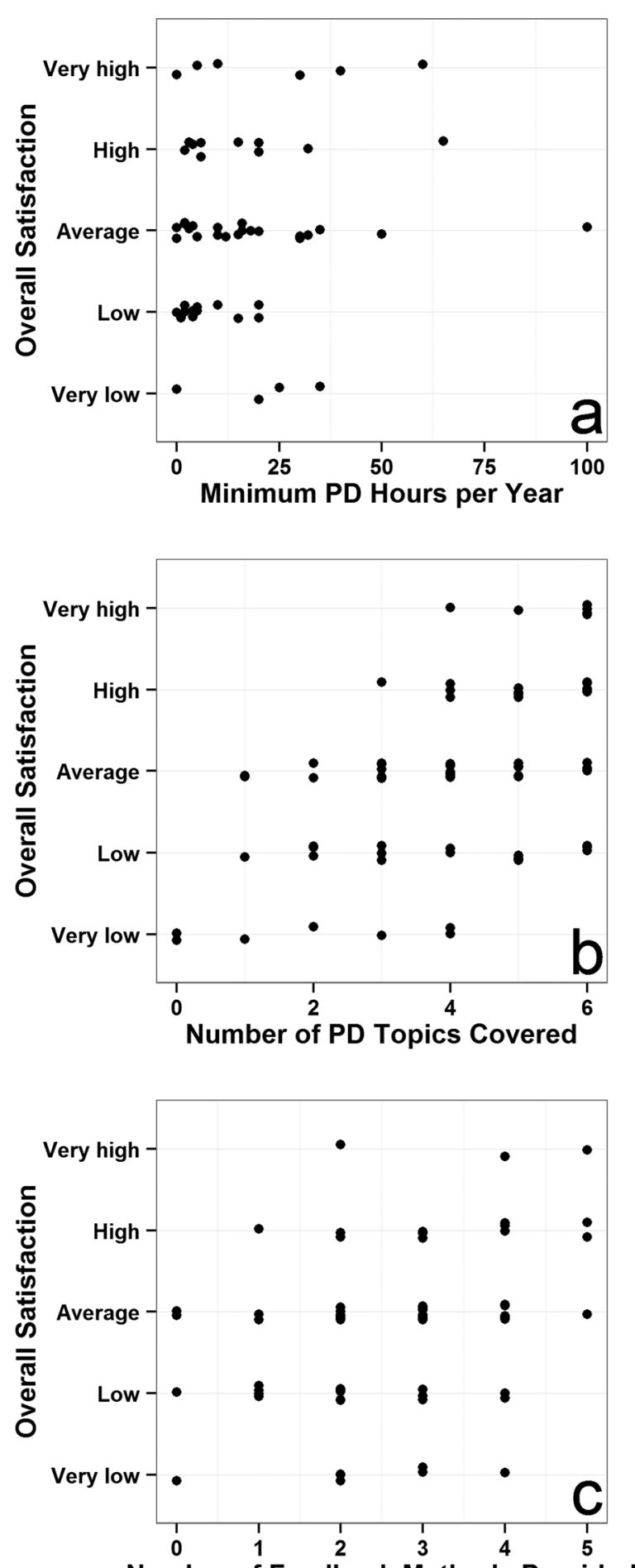

Figure 5. Scatter plots showing the relationship between respondents' self-reported overall satisfaction with their GTA PD programs and (a) minimum number of mandatory PD hours provided per year, (b) number of different topics covered in PD sessions, and (c) number of different types of mandatory or optional feedback provided to GTAs. Only the number of different topics covered in PD sessions (b) was significantly positively related to self-reported satisfaction $(p=0.001)$. 
Table 2. Comparison of the findings of Rushin et al. (1997) with our survey results regarding biology GTA PD

\begin{tabular}{lcc}
\hline \multicolumn{1}{c}{ Training categories } & $\begin{array}{c}\text { Rushin et al. } \\
(N=153)\end{array}$ & $\begin{array}{c}\text { Schussler } \text { et al. } \\
(N=71)\end{array}$ \\
\hline No training & $49 \%$ & $4 \%$ \\
Faculty mentoring & $7 \%$ & $0 \%$ \\
Pre-academic year & $22 \%$ & $92 \%$ \\
$\quad$ workshop & & \\
Required seminar & $14 \%$ & $4 \%$ (in-semester PD only) \\
Formal course & $8 \%$ & $4 \%$ for both categories \\
\hline
\end{tabular}

category. None of the schools in the current survey relied solely on mentoring by a faculty member as their source of PD.

\section{DISCUSSION}

The results of this survey provide an overview of the current state of PD teaching programs for biology GTAs at institutions across the United States and Canada. The comparison with the last national survey in 1997 suggests that institutional PD for biology GTAs has indeed changed. Almost all biology GTAs are now required to receive at least some formal PD for teaching, with a little more than half attending sessions both before and during the semester. While these results may indicate progress in formal training opportunities for biology GTAs, it was less encouraging to find that around half of the schools had 10 or fewer hours of total GTA PD per year and that most sessions only lasted $2-5 \mathrm{~h}$. Thus, although more formal preparation for teaching is required, it is likely not meeting the spirit of ongoing, time-intensive pedagogical preparation seen as best practice (Darling-Hammond and Richardson, 2009). Respondents who were most satisfied with their GTA PD programs discussed more of the six PD topics offered on the survey and self-rated their institutional support for GTA PD as high, suggesting that support for PD breadth may be an important goal for programs. Clearly, while the changes to biology GTA PD suggest a transition in the field since 1997, there is still little to indicate that the level of GTA PD for teaching is proportional to the importance of the role of GTAs in today's undergraduate classrooms.

One of the major findings regarding our first research question is that presemester PD is the most common mandatory type of formal GTA PD biology graduate students experience. Such orientations are more likely to be mandatory when they are course-specific versus departmental or institutional. This is discouraging, since the literature suggests that one-shot, short (most were 2-5 h) PD sessions are fairly ineffective for developing teaching abilities (Darling-Hammond and Richardson, 2009). At those institutions where GTA training programs are discipline-specific, GTAs receive more rigorous and structured PD with the aid of mentors who specialize in content pedagogy (Honeycutt et al., 2010; Ferzli et al., 2012). Although presemester orientations are certainly necessary to provide course background and set expectations for the semester, this is typically not the best time for integrating meaningful pedagogical theory into a PD program, because GTAs are not yet teaching and lack an understanding of what skills they will need or problems they will encounter while teaching (Hardre, 2012). Even this meager amount of PD is greater than at $12 \%$ of responding institutions, which had no mandatory presemester orientations at all, meaning there is no official venue for providing even basic instructional information before the semester begins for those GTAs.

In-semester PD for GTAs is generally less likely to be mandatory than presemester PD. This may be an effort to protect research time of GTAs (Boyer Commission on Educating Undergraduates in the Research University, 1998; Nyquist et al., 1999; Golde and Dore, 2001; Gardner and Jones, 2011) but may have other causes. For example, faculty and staff members may be unable to provide training during the semester or it may be lack of awareness on the part of biology programs that ongoing PD is better than a single workshop. The most common in-semester PD was found to take place during lab preparation meetings, with $40 \%$ of schools reporting this was mandatory. What is unknown from our survey results is the nature of the PD being provided during these sessions. Traditional lab preparation time is usually spent on reviewing the lab protocols and equipment/supplies (French and Russell, 2002; Wyse et al., 2014), suggesting that time for PD may be limited if it is provided in this context. However, there are models for how to integrate PD into lab preparation effectively (Nurrenbern et al., 1999; French and Russell, 2002; Wyse et al., 2014), and these sessions have the potential to provide continuous PD over a semester and be firmly situated within the discipline-specific and pedagogy-specific nature of labs (Brown et al., 1989). To maximize the utility of PD during lab preparation meetings, schools should try to minimize time for parts of lab preparation sessions that are less important (like supply lists or setups) and maximize time spent on instructional support for GTAs. The survey also uncovered the existence of many other optional in-semester PD activities available to GTAs to supplement their learning, including institutional and departmental pedagogical seminars. The challenge, however, is to identify and remove the barriers that apparently continue to prevent departments from making these opportunities mandatory so that all GTAs can receive a minimum amount of pedagogical preparation for their teaching roles.

Another interesting finding was that programs have a surprising amount of informal PD that could be expanded to provide the supplemental teaching support needed by GTAs. For instance, around $40 \%$ of programs are observing GTAs teach and providing feedback or discussing the results of student evaluations with GTAs. These are extremely important forms of instructional reflection that are often used by $\mathrm{K}-12$ teachers in training for improvement of practice and should be adopted by GTA PD programs (Gardner and Jones, 2011). Institutions could provide more formal structure to these programs by providing faculty and staff members support for these activities and by using validated observation protocols to improve and unify the feedback (Miller et al., 2014). One role for a network such as BioTAP may be to gather resources and protocols such as these and promote them as national models for best practices. Informal PD is often not perceived as a formalized practice that can improve instruction, yet given the limited amount of time that programs have for formal training, informal PD may be instrumental to helping increase GTA PD. 
Our second research question focused on the number of PD topics presented to GTAs in their programs, a factor found in this study to be positively related to respondents' satisfaction with their PD programs. Of the six topics offered as potential points of discussion in GTA PD sessions, it was not surprising that teaching policies and course management were the two that were discussed the most. Course logistics are often the first topics presented in PD sessions, because these are the first teaching concerns on which beginning teachers focus (Prieto, 2001). One surprising result, however, was the percentage of respondents who reported that they discussed teaching techniques. Although the length, quality, and content of this coverage is unknown, it is encouraging to know, particularly in light of the fact that $88 \%$ of the respondents are training GTAs to teach courses with an inquiry approach, that at least some time is being spent discussing instructional techniques. Of the six topics, however, the least presented in PD sessions were learning theory and lesson planning. This suggests that students may not be getting the type of instructional information that would truly support them in the delivery of an inquiry lab or course (particularly given how short most PD is reported to be).

Encouragingly, respondents are most interested in adding information about pedagogy and lesson planning to their PD sessions. There are many excellent models for how to add these topics into GTA PD (Hardre, 2005; Baumgartner, 2007; Schussler et al., 2008; Marbach-Ad et al., 2010, 2012a; Dotger, 2011; Lockwood et al., 2014); however, institutions clearly are not requiring semester-long PD courses for GTAs, so finding a structure that can maximize GTA learning while minimizing time away from research is critical. For instance, holding six 2-h-long sessions in one semester would not be particularly onerous for a GTA PD requirement and has been found to yield excellent instructional results (Marbach-Ad et al., 2012a). However, if the faculty or staff member leading the PD program is less familiar with lesson planning or pedagogical theory or how to effectively teach these topics, then this may be a barrier to adding these topics. In these cases, departments could ask a science faculty member who conducts education research to present this information or consider contracting out this training to their institutional teaching and learning center. Teaching and learning centers have the added benefit of bringing together GTAs across multiple disciplines to focus on best practices in teaching regardless of course type or topic. Departments could also create a GTA position for a qualified graduate student in a college of education or one conducting education research to supplement PD sessions on these topics.

Assessment of GTA PD programs and GTA instructional quality is clearly a developing but underutilized part of GTA PD programs at this time. This is likely a result of many programs not having a dedicated faculty or staff member who has time to both manage labs and assess the quality of PD programs. Nor is there an institutional imperative to measure GTA PD program effectiveness at this time. Given this, it is encouraging that so many programs do assess the quality of their efforts by student evaluations of GTAs and GTA teaching observations and even GTA surveys of satisfaction. Moreover, respondents indicated they would like to be introduced to validated national surveys to assess teaching. This indicates an awareness of the need to have empirical evidence of program quality, which may be a sign of increased undergraduate biology education research efforts across the nation. As mentioned previously, one thing a national network for GTA PD can do is suggest rubrics and surveys that have been successfully used for assessing instruction (e.g., COPUS [Smith et al., 2013] and OTAOP [Miller et al., 2014]) and could be used to assess GTA PD programs.

Finally, there is a positive correlation between perception of institutional support and respondent self-rating of programmatic GTA PD satisfaction. Receiving more institutional support from administrators and faculty members was also one of the desired changes respondents wanted to see in their programs. The question of how to get more institutional support for GTA PD is often not easy; nor is it easy to know who to approach for such support. Institutional teaching and learning centers may be one place to start with these efforts, since they often have connections with influential members of the administration and/or could help to initiate and sustain interdisciplinary collaborations for PD (Marbach-Ad et al., 2012b, 2015a). Working with institutional teaching and learning centers to develop cross-departmental GTA PD programs may also centralize some components of PD (Amundsen and Wilson, 2012) and bring additional visibility to these efforts. Departmental support may be generated by utilizing recent national reports like Vision and Change in Undergraduate Biology Education (AAAS, 2011) or Engage to Excel (PCAST, 2012) to emphasize the importance of instruction in gateway science courses. Some institutions may find that the key is to ask for a specific programmatic need, such as a few 2-h sessions for PD or a graduate assistant to help with GTA observations. On a national level, professional societies may also be key to promoting the importance of GTA PD for teaching. If they could focus their membership on the importance of introductory courses and the future role GTAs will play in national teaching efforts, they may garner more support from faculty members who have been otherwise reluctant to support teaching PD.

As noted previously, satisfaction of respondents with their PD programs was significantly positively related to the number of PD topics they presented to their GTAs and the institutional support they perceived for their programs. In open-ended responses, $43 \%$ of respondents wanted to be able to carry out GTA observations with feedback, and $39 \%$ of respondents said that the one thing they would change about their programs would be to provide more pedagogical training to their GTAs. Thus, survey responses suggest that programs looking to change their GTA PD may want to enlist institutional support to engage GTAs more meaningfully in pedagogical preparation and to provide feedback about their teaching. One path forward for programs may be to more carefully consider the overall purpose of their PD programs. As Amundsen and Wilson (2012) pointed out for faculty PD, programs tend to either focus on specific instructional outcomes (such as skills or methods) or on processes that improve instruction (such as reflection), and these perspectives impact the choice of PD practices. Regardless of purpose, however, the literature on $\mathrm{K}-12$ PD (Darling-Hammond and Richardson, 2009) suggests that this preparation needs to 
be provided in an ongoing manner and not as part of single presemester orientations.

This survey provided a snapshot of the biology GTA PD practices of a variety of institutions across the United States and Canada. As with all samples, care must be taken to not claim that these results represent the totality of institutions of that group. The self-report nature of the survey must also be taken into consideration. Respondents may have a very good understanding of their particular part of GTA PD but less of an understanding of institutional or departmental offerings available to GTAs. Because there are currently few ways to compare institutional GTA PD programs with others, self-reports of satisfaction or institutional support may not be empirically based. Self-response bias could also have impacted the results, with those being most eager to either praise or denigrate their institutions' efforts more likely to respond than others. It is also difficult to judge the nature of a program from survey responses. Two institutions may both report that they discuss learning theories in their PD sessions, but one may just mention this topic briefly, while another may spend a semester discussing various theories. As such, the results we present here should be considered a broad picture of what is happening at individual institutions, with specific details only possible through interviews or site visits.

\section{CONCLUSION}

This survey of institutional GTA PD practices provided a set of data that we believe can be used to inform institutions about how to develop biology GTAs as teachers. The comparison of our results with those of Rushin et al. (1997) suggests that many institutions or individual faculty or staff members at those institutions are rising to the challenge of providing formal PD opportunities to these key teachers of gateway and introductory biology courses. Our results suggest that expansion of sessions to provide more pedagogical preparation could enhance facilitators' satisfaction with the PD they provide to GTAs. Leaders of institutions should support this necessary teaching support to biology GTAs. As one of the respondents articulated, "We should be doing better with GTA pedagogical development or else all the education reform we are working on is a waste of time." The investment in GTAs as teachers truly is an investment in both the undergraduates of today and the faculty members of tomorrow. Providing more breadth in pedagogical training should not be viewed as a lost few hours of research productivity but instead as collective institutional and national gains that this time could yield in terms of instructional quality.

\section{ACKNOWLEDGMENTS}

The authors thank the other members of the BioTAP steering committee for their input into this study: Rosa Hainaj, Denise Kendall, Julie Luft, Susan Musante, Kimberly Tanner, and E. William Wichusen. Other contributors included Anna Jo Auerbach and Sarah Dalrymple. Several anonymous reviewers greatly improved the manuscript. This project was supported by a Research Coordination Network grant from the National Science Foundation to E.E.S. (DBI-1247938).

\section{REFERENCES}

Addy TM, Blanchard MR (2010). The problem with reform from the bottom up: instructional practices and teacher beliefs of graduate teaching assistants following a reform-minded university teaching certificate programme. Int J Sci Educ 32, 1045-1071.

American Association for the Advancement of Science (2011). Vision and Change in Undergraduate Biology Education: A Call to Action, Washington, DC.

Amundsen C, Wilson M (2012). Are we asking the right questions? A conceptual review of the educational development literature in higher education. Rev Ed Res 82, 90-126.

Ash D, Brown C, Kluger-Bell B, Hunter L (2009). Creating hybrid communities using inquiry as professional development for college science faculty. J Coll Sci Teach 38, 68-76.

Association of American Universities (2011). Undergraduate Education STEM Initiative. https://stemedhub.org/groups/aau (accessed 10 September 2014).

Austin AE (2002). Preparing the next generation of faculty: graduate school as socialization to the academic career. J High Educ 73, 94-122.

Austin AE, Campa H, Pfund C, Gillian-Daniel DL, Mathieu R, Stoddart J (2009). Preparing STEM doctoral students for future faculty careers. New Dir Teach Learn 117, 83-95.

Baumgartner E (2007). A professional development teaching course for science graduate students. J Coll Sci Teach 36, 16-21.

Bond-Robinson J, Rodriques RAB (2006). Catalyzing graduate teaching assistants' laboratory teaching through design research. J Chem Educ 83, 313-323.

Boyer Commission on Educating Undergraduates in the Research University (1998). Reinventing Undergraduate Education: A Blueprint for America's Research Universities, Stony Brook: State University of New York.

Brown JS, Collins A, Duguid S (1989). Situated cognition and the culture of learning. Educ Researcher 18, 32-42.

Brownell SE, Tanner KD (2012). Barriers to faculty pedagogical change: lack of training, time, incentives, and ... tensions with professional identity? CBE Life Sci Educ 11, 339-346.

Darling-Hammond L, Richardson N (2009). Teacher learning: what matters? Educ Leadership 66, 46-53.

DeChenne SE, Enochs LG, Needham M (2012). Science, technology, engineering, and mathematics graduate teaching assistants teaching self-efficacy. J Scholarship Teach Learn 12, 102-123.

Dotger S (2011). Exploring and developing graduate teaching assistants' pedagogies via lesson study. Teach High Educ 16, 157169.

Drasgow F (1986). Polychoric and polyserial correlations. In: The Encyclopedia of Statistics, vol. 7, ed. S Kotz and N Johnson, Hoboken, NJ: Wiley, 68-74.

Ferzli M, Morant T, Honeycutt B, Egan Warren S, Fenn M, Burns B (2012). Conceptualizing graduate teaching assistant development through stages of concern. In: Working Theories for Teaching Assistant Development: Time-Tested and Robust Theories, Frameworks, and Models for TA and ITA Learning, ed. G Gorsuch, Stillwater, OK: New Forums Press, 227-270.

Freeman S, Eddy SL, McDonough M, Smith MK, Wenderoth MP, Okoroafor N, Jordt H (2014). Active learning increases student performance in science, engineering, and mathematics. Proc Natl Acad Sci USA 111, 8410-8415.

French D, Russell C (2002). Do graduate teaching assistants benefit from teaching inquiry-based laboratories? BioScience 52, 1036-1041.

Gardner GE, Jones MG (2011). Pedagogical preparation of science graduate teaching assistant: challenges and implications. Sci Educ 20,31-41. 
Golde CM, Dore TM (2001). At Cross Purposes: What the Experiences of Today's Doctoral Students Reveal about Doctoral Education, Philadelphia, PA: Pew Charitable Trusts Report.

Gormally C, Brickman P, Hallar B, Armstrong N (2011). Lessons learned about implementing an inquiry-based curriculum in a college biology laboratory classroom. J Coll Sci Teach 40, 45-51.

Hardre PL (2005). Instructional design as a professional development tool-of-choice for graduate teaching assistants. Innov High Educ 30, 163-175.

Hardre PL (2012). Teaching assistant development through a fresh lens: a self-determination framework. In: Working Theories for Teaching Assistant Development: Time-Tested and Robust Theories, Frameworks, and Models for TA and ITA Learning, ed. G Gorsuch, Stillwater, OK: New Forums Press, 113-136.

Hardre PL, Burris AO (2012). What contributes to teaching assistant development: differential responses to key design features. Instruc Sci 40, 93-118.

Hardre PL, Chen C (2005). A case study analysis of the role of instructional design in the development of teaching expertise. Perform Improv Q 18, 34-58.

Honeycutt B, Ferzli M, Morant T, Egan Warren S (2010). An interdisciplinary approach to graduate TA training: a reflection of best practice. Studies Grad Prof Stud Develop 13, 138-152.

Hutcheson G (2013). GLM Models for Ordered and Unordered Categorical Response Variables. http://www.Research-Training.net/ Manchester (accessed 9 March 2015).

Kendall KD, Niemiller ML, Dittrich-Reed D, Chick LD, Wilmoth L, Milt A, Burt M, Lopes N, Cantwell L, Rubio L, et al. (2013). Departments can develop teaching identities of graduate students. CBE Life Sci Educ 12, 316-317.

Lockwood SA, Miller AJ, Cromie MM (2014). Preparing future biology faculty: an advanced professional development program for graduate students. Am Biol Teach 76, 17-21.

Luft JA, Kurdziel JP, Roehrig GH, Turner J (2004). Growing a garden without water: graduate teaching assistants in introductory science laboratories at a doctoral/research university. J Res Sci Teach 41, 211-233.

Marbach-Ad G, Egan L, Thompson KV (2015a). A Discipline-Based Teaching and Learning Center: A Model for Professional Development, New York: Springer.

Marbach-Ad G, Katz P, Thompson KV (2015b). A disciplinary teaching certificate program for science graduate students. J Teach Learn Centers (in press).

Marbach-Ad G, Schaefer KL, Kumi BC, Friedman LA, Thompson KV, Doyle MP (2012a). Development and evaluation of a prep course for chemistry graduate teaching assistants at a research university. J Chem Educ 89, 865-872.

Marbach-Ad G, Schaefer KL, Thompson KV (2012b). Faculty teaching philosophies, reported practices, and concerns inform the design of professional development activities of a disciplinary teaching and learning center. J Teach Learn Centers 4, 119-137.

Marbach-Ad G, Shields PA, Kent BW, Higgins B, Thompson KV (2010). Team teaching of a prep course for graduate teaching assistants. Studies Grad Prof Stud Develop 13, 44-58.
Maykut P, Morehouse R (1994). Beginning Qualitative Research. A Philosophic and Practical Guide, Washington, DC: Flamer Press.

Miller K, Oliver JS, Brickman P (2014). Enhancing teaching assistants' (TAs') inquiry teaching by means of teaching observations and reflective discourse. Sch Sci Math 114, 178-190.

Nurrenbern SC, Mickiewicz JA, Francisco JS (1999). The impact of continuous instructional development on graduate and undergraduate students. J Chem Educ 76, 114-119.

Nyquist JD, Manning L, Wulff DH, Austin AE, Sprague J, Fraser PK, Calcagno C, Woodford B (1999). On the road to becoming a professor: the graduate student experience. Change 31, 18-27.

Park C (2004). The graduate teaching assistant (GTA): lessons from North American experience. Teach High Educ 9, 349-361.

President's Council of Advisors on Science Technology (2012). Engage to Excel: Producing One Million Additional College Graduates with Degrees in Science, Technology, Engineering, and Mathematics, Washington, DC: U.S. Government Office of Science and Technology.

Prieto LR (2001). The supervision of teaching assistants: theory, evidence, and practice. In: The Teaching Assistant Training Handbook, ed. LR Prieto and SA Meyers, Stillwater, OK: New Forums Press, 103-129.

R Core Team (2014). R: A Language and Environment for Statistical Computing, Vienna, Austria: R Foundation for Statistical Computing. www.R-project.org (accessed 9 March 2015).

Rushin JW, DeSaix J, Lumsden A, Streubel DP, Summers G, Bernson C (1997). Graduate teaching assistant training: a basis for improvement of college biology teaching and faculty development? Am Biol Teach 59, 86-90.

Sauermann H, Roach M (2012). Science PhD career preferences: levels, changes, and advisor encouragement. PLoS One 7, e36307.

Schussler EE, Torres LE, Rybczynski S, Gerald GW, Monroe E, Sarkar P, Shahi D, Osman MA (2008). Transforming the teaching of science graduate students through reflection. J Coll Sci Teach 38, 32-36.

Smith MK, Jones FHM, Gilbert SL, Wieman CE (2013). The Classroom Observation Protocol for Undergraduate STEM (COPUS): a new instrument to characterize university STEM classroom practices. CBE Life Sci Educ 12, 618-627.

Sundberg MD, Armstrong JE, Wischusen EW (2005). A reappraisal of the status of introductory biology laboratory education in US colleges and universities. Am Biol Teach 67, 525-529.

Tanner KD, Allen D (2006). Approaches to biology teaching and learning: on integrating pedagogical training into the graduate experiences of future science faculty. Cell Biol Educ 5, 1-6.

Trautwein SN (1999). From teaching assistant to educator: beginning steps on the professional path. J Grad Teach Assist Dev 7, 19-26.

Wyse SA, Long TM, Ebert-May D (2014). Teaching assistant professional development in biology: designed for and driven by multidimensional data. CBE Life Sci Educ 13, 212-223.

Young SL, Bippus AM (2008). Assessment of graduate teaching assistant (GTA) training: a case study of a training program and its impact on GTAs. Comm Teach 22, 116-129. 